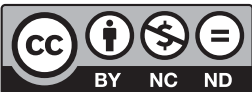

Estudos Teológicos foi licenciado com uma Licença Creative Commons Atribuição - NãoComercial - SemDerivados 3.0 Não Adaptada

http://dx.doi.org/10.22351/et.v60i2.4075

\title{
A História do MEdo ReVisitada: ÉTICA DA ALTERIDAde FRENTE À COVID-19 COMO UMA PANDEMIA do SÉCULO XXI ${ }^{1}$
}

The history of fear revisited:

Ethics of alterity in front of Covid-19 as a 21st century pandemic

\section{Ivo dos Santos Canabarro ${ }^{2}$ \\ Bianca Strücker ${ }^{3}$ Noli Bernardo Hahn ${ }^{4}$}

\begin{abstract}
Resumo: O artigo tem como tema central discutir como uma pandemia do século XXI, a Covid-19, conseguiu trazer ao tempo presente as novas representações do medo da morte e o papel da alteridade no cuidado com a coletividade. Discute-se, com aportes teóricos, como a construção do medo da morte é uma permanência dos tempos passados das pestes e epidemias. A pergunta norteadora é: como enfrentar o medo da morte diante da pandemia do novo coronavírus? A hipótese apresentada direciona para a ética da alteridade, do cuidado com o Outro. Para alcançar os objetivos, divide-se o artigo em duas sessões: a primeira revisita as representações imaginárias sobre a morte e o medo da finitude da vida frente à pandemia. A segunda sessão é direcionada à discussão sobre a importância das relações de alteridade e respeito com a vida do Outro. A reflexão mescla, em termos metodológicos, as abordagens histórico-analítica e complexo-paradoxal.
\end{abstract}

Palavras-chave: Covid-19. Medo. Morte. Alteridade. Direitos humanos.

Abstract: The central theme of the article is to discuss how a 21 st century pandemic, Covid-19, managed to bring to the present time the new representations of the fear of death and the role of otherness in caring for the community. It is discussed, with theoretical contributions, how the construction of fear of death is a permanence of the past times of pests and epidemics. The guiding question is: how to face the fear of death in the face of the new coronavirus pandemic? The presented hypothesis leads to

1 O artigo foi recebido em 29 de julho de 2020 e aprovado em 28 de setembro de 2020 com base nas avaliações dos pareceristas ad hoc.

2 Doutor. UNIJUI, Ijuí, RS. E-mail: ivo.canabarro@unijui.edu.br

3 Mestre. Universidade Regional Integrada do Alto Uruguai e das Missões - URI [pesquisadora bolsista da CAPES]. E-mail: biancastrucker@hotmail.com

4 Doutor. Universidade Regional Integrada do Alto Uruguai e das Missões (URI), Campus de Santo Ângelo, RS. E-mail: nolihahn@san.uri.br 
the ethics of otherness, of caring for the other. To achieve the objectives, the article is divided into two sections: the first revisits the imaginary representations about death and fear of the finitude of life in the face of the pandemic. The second session discusses the importance of otherness and respect for the other's life. The reflection mixes, in methodological terms, the historical-analytical and complex-paradoxical approaches.

Keywords: Pandemic. Covid-19. Fear. Death. Alterity. Human rights.

\section{Introdução}

O limiar do século XXI nos trouxe uma série de novas preocupações que acreditávamos estarem superadas. O tempo presente nos mostra que ainda é possível passar por experiências que já foram vivenciadas por outras sociedades, como epidemias e pandemias. O medo voltou a ser uma preocupação, tanto individual como coletiva, e a ameaça não está mais num patamar distante, em algum lugar específico, mas está em todos os lugares, nos cinco continentes.

O mundo vive um novo medo, o medo da morte pelo novo coronavírus, frente aos noticiários que diariamente atualizam os números de mortos. Uma pandemia mostra nossa fragilidade, ameaça nossa existência de forma cruel, pois o número de mortos aumenta a cada dia que passa, totalizando somas assustadoras. $\mathrm{O}$ avanço crescente da pandemia também nos revela o perigo nos países e nas regiões mais pobres, onde as condições sanitárias são precárias e expõem toda a população ao perigo do contágio. Em locais onde existem conglomerações humanas mais acentuadas o risco se acentua, pois se torna mais difícil manter o isolamento social. A própria organização de alguns espaços urbanos coloca as pessoas em situação de risco, isto é, onde todos convivem em espaços coletivos, o distanciamento físico é mais difícil, como populações silvícolas, a exemplo das populações indígenas brasileiras, com dificuldades de isolamento devido às condições de vivências em culturas coletivas.

Quando o medo coletivo volta a rondar nosso imaginário, várias representações são elaboradas com a finalidade de dar algum tipo de respostas às nossas indagações e vazios existenciais. O medo da morte está presente em cada indivíduo. O medo apresenta-se num imaginário, por vezes, muito propagado pelas religiões. Somos colocados em um lugar de inferioridade perante a vida divina, o que faz com que muitas pessoas acentuem a dicotomia fé e razão. Pesquisas em diferentes laboratórios ao redor do mundo estão apresentando avanços científicos na busca de uma vacina eficaz contra a Covid-19. Não podemos tomar uma posição negacionista das descobertas científicas que foram, também, fundamentais para a cura e prevenção de outras doenças ao longo da história. Os credos podem ser complementares às terapias, mas não às substituem.

O artigo está organizado em duas sessões complementares. Uma inicial, com considerações conceituais sobre o medo e sua construção tanto individual como coletiva, seguida de uma análise da pandemia da Covid-19 no século XXI relacionada à ética da alteridade, do olhar para o Outro. A pergunta norteadora é: como enfrentar o medo da morte diante da pandemia do novo coronavírus? A hipótese apresentada 
direciona para a ética da alteridade, do cuidado com o Outro. A primeira sessão é baseada exclusivamente em importante obra histórica que foi revisitada para este artigo, o livro de Jean Delumeau, História do medo no Ocidente ${ }^{5}$, é a principal referência. Considerada como uma obra clássica sobre o medo na história, ela nos propicia a análise de como o medo foi construído e vivido ao longo da história. Entendemos que é fundamental trazer essas análises para o tempo presente, pois o medo da morte nos colocou num outro lugar, no locus do medo, da nossa fragilidade de lidar com a doença.

A segunda sessão do artigo aborda a ética da alteridade como uma resposta, um caminho de cuidado coletivo, voltado à outridade. Especialmente ancorados na obra de Emmanuel Lévinas, Totalidade e Infinito ${ }^{6}$, que apregoa o cuidado do Eu para o Outro como um elemento constitutivo da humanidade, é traçado um paralelo com a experiência do tempo presente, em que os cuidados até então comprovados para o combate ao novo coronavírus dependem de adesão coletiva. Dessa forma, por meio de uma abordagem complexo-paradoxal, se inter-relacionam saberes filosóficos, das ciências da saúde e teológicos, a fim de problematizar a sociedade contemporânea, marcada pelo individualismo, e repensar a atomização do ser humano frente a problemas que exigem noções comunitárias, como a pandemia da Covid-19.

\section{Reviver o medo no século XXI: permanências de um passado distante}

A sessão tem como objetivo revisitar a história do medo e contextualizá-la no tempo presente, como uma permanência do passado que ressurge diante da ameaça causada pelo novo coronavírus (Covid-19). Serão considerados alguns pressupostos trabalhados por Jean Delumeau em sua clássica obra A história do medo no Ocidente, publicada na França em 1978. A obra faz parte de um conjunto de reflexões sobre o medo e, principalmente, como ele foi construído e utilizado como forma de dominação. $\mathrm{O}$ autor começa a obra discutindo que toda a civilização é produto de uma longa luta contra o medo $^{7}$, o que nos coloca em outro patamar de discussões, ou seja, como questões que são do domínio público passam a interferir no mundo privado. $\mathrm{O}$ medo se restringe apenas à individualidade, mas faz parte de todo um conjunto de representações que permeiam os imaginários sociais em distintas sociedades ao longo de suas trajetórias.

Segundo Delumeau ${ }^{8}$, o medo como imaginário coletivo assolou todo o continente europeu e se espalhou pelo mundo. O período entre 1348 a 1800 foi o mais cruel em termos de pestes e pandemias. As pestes causaram tantas mortes, que a população tinha medo até de sair de casa, o que repercute no mundo atual, como uma forma de permanência do medo. O que vivemos no século XXI, com o isolamento social,

\footnotetext{
DELUMEAU, Jean. A história do medo no ocidente 1300-1800: Uma cidade sitiada. Trad. Maria Lucia Machado. São Paulo: Companhia das Letras, 2009.

6 LEVINAS, Emmanuel. Totalidade e infinito. Trad. José Pinto Ribeiro. Lisboa: Edições 70, 1980.

7 DELUMEAU, 2009, p. 13.

8 DELUMEAU, 2009, p. 13.
} 
não é apenas uma medida restritiva de distanciamento social, é, paradoxalmente, uma forma de proteção e de medo de contágio do novo vírus. A representação do medo é significada de diferentes formas ao longo da história, ela é contextual, ressignificada de acordo com o tempo presente de cada sociedade.

Historicamente, Delumeau ${ }^{9}$ acentua que o medo está carregado de tanta vergonha que o escondemos devido a uma noção de culpa por termos o medo. Em algumas sociedades, o medo estava atrelado à covardia ${ }^{10}$, ou seja, o indivíduo que sentia algum medo era um covarde. A vivência das guerras forjou a necessidade de impor-se como portador da coragem. Vitoriosos eram corajosos; perdedores, medrosos. Essa constatação era uma forma de dominação pelo medo: aqueles que dominavam eram os mais destemidos, aqueles que obedeciam deveriam temer seus superiores, por isso o medo era instituição de poder. ${ }^{11}$ A classe e o sexo embasavam uma estrutura social onde o temor era uma forma ideológica de imposição do poder. ${ }^{12}$

Pode-se analisar o medo a partir de duas distintas dimensões: a individual e a coletiva. Como ambas se complementam e se entrelaçam, é difícil estabelecer um limite entre os elementos que são próprios dos indivíduos e os que são de domínio do coletivo. Mesmo os estudos psicanalíticos têm dificuldade de estabelecer as barreiras da mente humana, de seu ambiente e laços de pertencimento. Delumeau ${ }^{13}$ observa que, embora em nossa contemporaneidade haja mais sensibilidade em relação ao medo, não é apenas a covardia que era determinada socialmente, o medo pode ser considerado um componente da experiência humana. Fazemos esforços contínuos para superá-lo, mas ele está dentro de cada um de nós, indivíduos historicamente datados numa determinada sociedade.

O medo, como característica humana, é tão forte e presente em cada um de nós, que acompanha-nos por toda a nossa existência. $\mathrm{O}$ autor ressalta ${ }^{14}$ que o medo nasceu com o ser humano, portanto seu processo de superação pode ser momentâneo e, a qualquer momento, retornar à nossa objetivação, que o ressignifica de outra forma em diferentes situações. Esse ressurgimento do medo, com formas e signos próprios de cada época, é enfrentado no atual momento, pois não estávamos preparados para um inimigo invisível como um vírus; as sociedades estavam mais preocupadas com as guerras nucleares, inclusive com a construção de bombas e tecnologias para uma possível guerra dessa natureza.

Delumeau $^{15}$ acentua que não ter medo não é natural, deixar de sentir medo não tem nada a ver com coragem, essa relação entre medo e coragem é uma datação histó-

9 DELUMEAU, 2009, p. 14.

${ }^{10}$ DELUMEAU, 2009, p. 14-15.

${ }_{11}$ Michel Foucault teoriza sobre a arqueologia e genealogia do poder. Em sua obra, teoriza como o medo pode, no passado e no presente, ser utilizado para delimitar o alcance do poder de quem o detém. As punições foram, e em muitos momentos ainda são, espetaculosas para que não gerem apenas justiça, mas medo naqueles que assistem ao espetáculo (FOUCAULT, 2019).

12 FOUCAULT, 2019, p. 284-286.

${ }_{13}$ DELUMEAU, 2009, p. 19.

${ }^{14}$ DELUMEAU, 2009, p. 20.

15 DELUMEAU, 2009, p. 20-23. 
rica, portanto uma construção, pois, em muitas batalhas, os soldados não poderiam ter medo, deveriam ser essencialmente corajosos para vencer os inimigos. Isso construiu uma representação de coragem que nos acompanha até o tempo presente, é uma forma de comprometer nossa sensibilidade, porque coloca os seres humanos num patamar em que o sofrimento é uma forma de covardia. Esse contexto criou uma representação de masculinidade em que os seres humanos não podem sofrer, não podem ter medo de nada. ${ }^{16}$ Todavia, por mais que se criem representações sobre a coragem e a superação dos medos, os seres humanos sempre têm medo da morte.

O medo da morte é presente tanto no mundo ocidental como no oriental. Numa pandemia, como estamos vivenciando, o medo da morte ronda nosso imaginário, inclusive com as restrições dos seus ritos de passagem, que estão simbolicamente proibidos em diversos países do mundo. Não se pode ter o culto ao morto, o corpo não pode estar presente nos rituais de despedidas, como é de costume para muitas religiões e culturas. Trata-se de uma quebra de rituais de difícil entendimento para as sociedades que cultural e espiritualmente faziam rituais de despedida de seus mortos.

Delumeau ${ }^{17}$ observa com clareza que insegurança é o símbolo da morte, e segurança é o símbolo da vida. A insegurança, como símbolo da morte, é essencialmente uma forma de perigo iminente, gerando ainda mais medos. A segurança, como símbolo de vida, nesta pandemia surge de forma delicada, pois medidas protetivas são elaboradas na perspectiva de garantir saúde, mas criou-se um novo imaginário, uma vida pós-pandemia. Segurança e insegurança são individuais e coletivas. Vivemos em um mundo social no qual essas duas dimensões se atravessam a todo momento, portanto somos seres sociais por excelência. Segundo Delumeau ${ }^{18}$, essas dimensões são totalmente permeáveis, pois o medo individual tem reações específicas e, ao mesmo tempo, interligadas.

O mesmo autor ainda observa que o medo individual também provoca uma tomada de consciência do perigo, de algo que pode ser urgente e momentâneo, como de algo que possa nos comprometer para o restante de nossas vidas. ${ }^{19}$ Delumeau ${ }^{20}$ enfatiza que o medo coletivo pode ser expresso em diferentes formas de reações, como uma multidão tomada pelo pânico. O medo como ameaça é um ponto nodal, pois a pandemia representa uma ameaça coletiva à nossa existência, não ameaça alguns

${ }^{16}$ Ainda que o medo seja uma característica universal da humanidade, foi utilizado pelos discursos patriarcais para delimitá-lo como uma fraqueza, uma sensibilidade e, assim, uma característica feminina. Sentir medo passou a ser tratado apenas como parte da natureza feminina. Esses papéis construídos e impostos pela cultura patriarcal ainda são notados em nossa sociedade, homens não podem chorar, não podem sentir medo, devem ser fortes, corajosos e destemidos. Relacionando com o cuidado com a saúde, estudos apontam que mulheres têm mais cuidado com seu corpo e sua saúde. Enquanto isso há um menor percentual de homens que fazem exames periodicamente (GOMES; NASCIMENTO; ARAÚJO, 2006). Assim, resumidamente, pode-se apontar que o marcador pautado no sexo do medo impõe um maior descaso de homens com a sua própria saúde, mas também com a saúde coletiva.

17 DELUMEAU, 2009, p. 25.

${ }_{18}^{18}$ DELUMEAU, 2009, p. 27.

${ }_{19}$ DELUMEAU, 2009, p. 30.

${ }^{20}$ DELUMEAU, 2009, p. 31. 
indivíduos específicos, mas todos os grupos humanos. Quando o medo é também coletivo, alguns grupos acreditam que não serão afetados e outros acreditam que pode ameaçar a sua existência. $\mathrm{O}$ medo coletivo interfere diretamente em cada indivíduo, pode causar pânico incontrolável, inclusive, órgãos de saúde recomendam cuidado com a saúde mental das pessoas que passam muito tempo isoladas.

O pânico aparece como uma criação coletiva, e a circulação de notícias sobre o aumento de infectados, de mortos, de possibilidades de novas ondas de contágio reforçam o medo individual e coletivo. Esse medo coletivo cria diferentes representações no imaginário social, pânico que pode ameaçar a saúde mental das pessoas que permanecem isoladas e sem muito contato com o coletivo, ou de pessoas que não podem aderir ao isolamento social devido a necessidades econômicas.

Um dos sintomas do medo coletivo e individual é a ameaça de morte que uma pandemia pode causar. As pessoas recorrem às crenças religiosas, numa tentativa de arrepender-se dos pecados ou em busca de consolação espiritual. Entretanto, não existem certezas em uma pandemia, a insegurança é presente em todos os momentos nesses períodos. Deste modo, as crenças podem se apresentar como certezas frente à insegurança em que estamos vivendo. ${ }^{21}$ Mas, infelizmente, no mundo inteiro são notadas manifestações negacionistas da ciência, o que, paradoxalmente, pode colocar em risco a credibilidade de todo o trabalho dos cientistas que apostam em suas pesquisas na descoberta de vacinas, medicação preventiva e curativa, ou da própria espiritualidade, quando opta por alinhar-se a pensamentos negacionistas.

As medidas protetivas recomendadas pela Organização Mundial da Saúde (OMS) e demais órgãos sanitários, as quais seguem protocolos médicos preventivos e são utilizadas para combater o contágio pelo vírus, portanto de extrema necessidade, são, muitas vezes, desacreditadas por indivíduos ou grupos sociais. Alguns grupos fundamentalistas duvidam de sua eficácia e propagam a inutilidade das medidas sanitárias, o que pode colocar em risco a vida de indivíduos e grupos. Delumeau ${ }^{22}$ observa que o uso das máscaras nas pestes e epidemias foi uma prática comum, e os médicos sempre as utilizaram como proteção. $\mathrm{O}$ autor nos descreve a máscara, ao mesmo tempo, como tradução do medo e de defesa contra o medo, pois se, por um lado, protege, por outro, gera medo, como um símbolo à mostra da ameaça invisível dos vírus e das bactérias.

Nas observações de Delumeau ${ }^{23}$, as pestes e epidemias foram muito acentuadas num longo período, de 1348 a 1720, séculos de maior propagação. Nesse ínterim, o autor estima que as pestes que assolaram o planeta dentro desse recorte temporal eliminaram cerca de um terço da população do mundo. Posterior a esse período, outras pandemias e epidemias dizimaram muitas vidas, como a chamada Gripe Espa-

${ }^{21}$ O filósofo e político italiano Gianni Vattimo debate acerca da verdade dentro da perspectiva cristã, como uma certeza, como algo absoluto, imutável, aistórica. $\mathrm{O}$ autor defende uma ontologia da atualidade, onde a verdade e Deus devem ser contextuais, presentes, históricos (VATTIMO, 2016). Portanto, ainda que a espiritualidade possa ser vista um refúgio, não deve ser um espaço de negação do tempo presente, das mazelas próprias de cada momento histórico.

22 DELUMEAU, 2009, p. 32.

${ }^{23}$ DELUMEAU, 2009, p. 154. 
nhola. ${ }^{24}$ Com o avanço tecnológico e científico, enganosamente, apagamos da memória a possibilidade de vivenciarmos uma pandemia no tempo presente. Entretanto, estudos associam a destruição da natureza e o consumo exacerbado de carne, por exemplo, com o surgimento de novas doenças ${ }^{25}$, para as quais não temos imunidade nem medicamentos desenvolvidos, portanto capazes de gerar mais mortes. Coletiva e individualmente imaginamos que a ciência já disponível seria capaz de barrar doenças potencialmente tão mortais.

Entretanto, no começo do século XXI, nos deparamos com uma situação singular: o medo de que muitas vidas sejam perdidas foi imposto por um vírus e não por uma bomba nuclear, como se poderia imaginar. Espalhou-se um novo medo, talvez já amortecido no imaginário social, e evidenciou uma nova fragilidade: ao mesmo tempo em que sabemos que os credos não curam, que é preciso ciência para desenvolver vacinas e medicamentos, também se sabe da importância da espiritualidade ao dar conforto em momentos de tamanha angústia social, quando o medo da morte que nos ronda por todos os lados.

A pandemia da Covid-19 nos fez revisitar os medos, evidenciando um sentimento de fragilidade e impotência. Delumeau ${ }^{26}$, ao teorizar sobre o medo da morte, preconiza que o ser humano nada pode contra a morte, mas, com a ajuda de Deus, the é possível evitar as penas eternas. $\mathrm{O}$ autor retrata uma postura religiosa frente à morte, nos mostrando certa impotência do ser humano em lidar com a morte, mas que é tematizada de diferentes formas pelas inúmeras religiões como último rito de passagem do ser humano.

Em continuidade, abre-se a reflexão à ética da alteridade, tema pertinente para o despertar do cuidado em relação ao Outro em tempos de permanência do medo.

\section{A ética da alteridade e de cuidado do Outro em tempos de pandemia}

Conforme definição do dicionário de saúde, pandemia é "epidemia que se estende a quase todos os habitantes de uma região e que pode compreender uma zona geográfica muito vasta" ${ }^{27}$. Pode-se dizer que os termos epidemia e endemia são os mais antigos da medicina ${ }^{28}$, devido à preocupação que doenças de proporções massivas podem gerar. Pandemia, palavra de origem grega, formada com o prefixo neutro pan, que tem o sentido de todos/totalidade, e demos, povo, foi empregada pela pri-

\footnotetext{
${ }^{24}$ Melhor nomeada como gripe de 1918, pois não tem comprovações de ter surgido na Espanha, foi uma vasta e mortal pandemia do vírus influenza. Estima-se que, entre 1918 e 1920, produziu de 50 a 100 milhões de óbitos, 35 mil só no Brasil (TASCHNER, 2020).

${ }^{25}$ PAIM, Cynthia Schuck; ALONSO, Wladimir J. Pandemias: saúde global e escolhas pessoais. Alfenas: Cria editora, 2020.

${ }^{26}$ DELUMEAU, 2009, p. 302.

${ }^{27}$ SILVA, Carlos Roberto Lyra da; SILVA, Roberto Carlos Lyra da. Dicionário de saúde. 6. ed. São Caetano do Sul: Yendis, 2007. p. 454.

${ }^{28}$ REZENDE, Joffre Marcondes de. Epidemia, Endemia, Pandemia e Epidemiologia. Linguagem Médica, v. 27, p. 153-155, jan./jun. 1998.
} 
meira vez por Platão. ${ }^{29}$ Platão empregou a palavra em sentido genérico, referindo-se a qualquer acontecimento capaz de alcançar toda a população.

Assim, sintetizando, considera-se pandemia uma doença capaz de afetar uma grande massa populacional em muitos lugares do planeta. Essa conceituação torna-se importante para refletir a relação com o Outro ${ }^{30}$, sobretudo na sociedade contemporânea, fortemente marcada pelo individualismo e consumo. ${ }^{31} \mathrm{~A}$ contemporaneidade comporta o desafio em tempos de pandemia de, ao mesmo tempo, conviver com as individualidades exacerbadas e gerar uma ética de alteridade ${ }^{32}$ que faça com que esses indivíduos se preocupem com outros, com o planeta.

A peculiaridade que a Covid-1933 apresenta é ter um grupo que corre risco de morrer decorrente da contaminação bastante demarcado (salvo exceções, idosos e portadores de comorbidades/doenças crônicas). ${ }^{34}$ Porém apenas os cuidados desse grupo populacional não são suficientes para restringir a circulação do vírus, de maneira que se faz necessária uma colaboração coletiva de cuidado. ${ }^{35}$ Isto é, se apenas pessoas idosos, pessoas que sofrem de doenças crônicas, acamadas, dentre outras pertencentes ao chamado grupo de risco para a Covid-19 tomarem as medidas sanitárias sugeridas pela comunidade científica internacional e a OMS, não seria o suficiente para conter a propagação do vírus. Também, ainda que seja em menor probabilidade, o novo coronavírus não se agravou apenas em pacientes do grupo de risco. Diversas pessoas jovens, atletas e saudáveis sofreram com as complicações geradas pela doença, que, inclusive, levou muitas ao óbito.

${ }^{29}$ PLATÃO. Leis e Epínomes. Trad. Carlos Alberto Nunes. Pará: Universidade Federal do Pará, 1980. v. 12.

${ }^{30}$ Linguagem proveniente das classificações de Emmanuel Lévinas. "O Outro metafísico é outro de uma alteridade que não é formal, de uma alteridade que não é um simples inverso da identidade, nem de uma alteridade feita de resistência ao Mesmo, mas de uma alteridade anterior a toda a iniciativa, a todo o imperialismo do Mesmo; Outro de uma alteridade que não limita o Mesmo, porque nesse caso o Outro não seria rigorosamente Outro: pela comunidade da fronteira, seria, dentro do sistema, ainda o Mesmo. O absolutamente Outro é Outrem; não faz número comigo. A coletividade em que eu digo 'tu' ou 'nós' não é um plural de ‘eu'. Eu, tu, não são indivíduos de um conceito comum” (LÉVINAS, 1980, p. 26).

31 BAUMAN, Zygmunt. Comunidade. A busca por segurança no mundo atual. Trad. Plínio Dentzien. Rio de Janeiro: Jorge Zahar, 2003. p. 59-60.

32 No pensamento levinasiano é possível associar a realização do ser humano à questão da alteridade, isto é, do reconhecimento de um Outro que, por definição, não pode ser reduzido a um mesmo. O Outro, na alteridade, é um rosto que se apresenta diante do Eu, em uma relação face à face, e que exige do Eu um comportamento ético que o permita ser, isto é, existir outramente (LÉVINAS, 1980).

33 Em 11 de março de 2020, o diretor-geral da Organização Mundial da Saúde (OMS), Tedros Adhanom Ghebreyesus, declarou que a Covid-19, doença causada pelo novo coronavírus - SARS-CoV-2, passou a ser caracterizada como uma pandemia (OPAS. Organização Pan-americana de Saúde. OMS afirma que COVID-19 é agora caracterizada como pandemia. 11 mar. 2020. Disponível em: < https://www.paho. org/bra/index.php?option=com_content\&view=article\&id=6120:oms-afirma-que-covid-19-e-agoracaracterizada-como-pandemia\&Itemid=812>. Acesso em: 22 jul. 2020a.).

34 OPAS. Organização Pan-americana de Saúde. Orientação sobre o uso de máscaras no contexto da COVID-19: Orientação provisória 5 de junho de 2020. 05 jun. 2020. Disponível em: < https://iris.paho. org/bitstream/handle/10665.2/52254/OPASWBRACOVID-1920071_por.pdf?sequence=1\&isAllowed=y $>$. Acesso em: 22 set. 2020 b. p. 7.

35 OPAS, 2020b, p. 1. 
Assim, as dificuldades e novas rotinas impostas pela Covid-19 expuseram a fragilidade da vida humana quando tratada apenas na individualidade. Somos seres sociais $^{36}$, que vivem em coletividade e que dependem uns dos outros para garantir a própria existência. Essa necessidade da coletividade para proteger a vida do Outro e a minha coloca a cultura ocidental em questionamento ${ }^{37}$ diante da crescente e aguçada individualização, dos encastelamentos sociais. Diante desse contexto, especialmente a responsabilidade com o Outro, a ética da alteridade, de cuidado com aqueles que não conheço são respostas para um momento pandêmico.

De acordo com Emmanuel Lévinas ${ }^{38}$, a ética da alteridade defende a concepção de que somos responsáveis uns pelos outros, que a relação com o Outro, com sua segurança, seu bem-estar é de nossa responsabilidade. $\mathrm{Ou}$, dito de outro modo, nossa responsabilidade com a vivência do Outro é total, indeclinável e intransferível, não pautada em uma ética contratualista ou principiológica, mas em uma ética que se dá de forma gratuita e espontânea. À medida que somos negligentes e imprudentes no cuidado ao Outro, estamos falhando eticamente, estamos em falta com a nossa posição de responsabilidade e boa vivência em relação ao Outro. Por conseguinte, no pensamento levinasiano, a humanidade existe a partir da ética, a relação interpessoal pressupõe uma dimensão ética a partir da compreensão de que o Outro é nossa responsabilidade, e isso nos humaniza.

Levando em consideração o momento de crise sanitária causada e evidenciada pela pandemia do novo coronavírus, os atos de descaso para com a saúde e o bem-estar do Outro para priorizar o mercado fazem com que a noção de ética levinasiana e de alteridade sejam ultrajadas, pois, ao negar os cuidados necessários para com o Outro, nega-se a responsabilidade com aquela vivência, banaliza-se a existência da outridade. Por outro lado, o momento exige nosso cuidado com o Outro e conosco mesmos, e ao atender as medidas de proteção ${ }^{39}$, se reacende a relação de alteridade da vivência ética. É o sentido apresentado por Hannah Arendt ${ }^{40}$, o que nos torna humanos é a relação entre indivíduos, não podemos nos atomizar, a acepção humanista mais pura, que se preocupa acima de tudo com a condição humana.

A crise humanitária, econômica e de saúde imposta pela pandemia do novo coronavírus é avassaladora, marcada pela tragédia de milhões de mortes e um inimigo invisível e impiedoso. Cabe demarcar a assimetria dos impactos gerados ${ }^{41}$, os momentos de crise evidenciam as desigualdades já existentes na sociedade moderna: pobreza, falta de saneamento básico, acesso à água potável, moradia adequada, alimentação nutritiva, dentre outros. Também escancara a descartabilidade da vida, especialmente

${ }^{36}$ LÉVINAS, 1980, p. 270.

37 BAUMAN, 2003, p. 115-120.

${ }_{38}$ LÉVINAS, 1980, p. 178-179.

${ }^{39}$ OPAS, 2020b, p. 12-13.

${ }^{40}$ ARENDT, Hannah. A Condição Humana. 10. ed. Rio de Janeiro: Ed. Forense Universitária, 2000.

${ }^{41}$ GOES, Emanuelle Freitas; RAMOS, Dandara de oliveira; FERREIRA, Andrea Jaqueline Fortes. Desigualdades raciais em saúde e a pandemia da Covid-19. Trabalho, educação e saúde, Rio de Janeiro, v. 18, n. 3, 2020. Disponível em: <https://preprints.scielo.org/index.php/scielo/preprint/view/635/816>. Acesso em: 22 set. 2020. 
de grupos mais vulneráveis. ${ }^{42}$ Falar em medo da morte diante de uma pandemia em um país tão desigual como o Brasil é falar de medos muito dissonantes. Da incerteza de ter um tratamento médico, da perda de renda e da convivência com outras mazelas, como violência, a depender da cor da pele, do credo e do endereço. Assim, embora a Covid-19 nos atinja de modo coletivo, que gera um sentimento de medo coletivo, na individualidade é muito diverso. Grupos populacionais vulneráveis são atingidos duas vezes: uma pelo vírus e outra pelos discrepantes contrastes de uma sociedade desigual. É um momento que clama pela ressignificação de muitos dos nossos valores e, em especial, uma reabilitação do referencial ético de nossas sociedades. ${ }^{43}$

Numa ótica individualista, preocupações com o bem comum e com o Outro em sua dimensão ética são substituídas por uma gramática que visa apenas ao eu, ao ego, ao consumo, ao imediatismo, com posturas apáticas para com o sofrimento da outridade $^{44}$, exacerbadamente hedonistas e narcisistas. Há também a retórica que defende o bem-estar alcançado pelo mérito, cada um faz por merecer, o culto do "cada um por si", do "se estou aqui é porque mereci", do sucesso pessoal por qualquer meio ${ }^{45}$, por meio de um processo de individualização e atomização das relações sociais ${ }^{46}$, em detrimento da alteridade, da solidariedade, da fraternidade e de projetos coletivos.

É nesse contexto de desaparecimento do cuidado com o Outro diante da individualização exacerbada, que nega o bem comum, a coletividade ou preocupações para além daquelas inerentes ao próprio desempenho, à produtividade, à competitividade e ao consumo, que surge a discussão sobre como a morte do Outro é vista por mim, especialmente durante a pandemia do novo coronavírus. Dentro desse espectro há a relativização da morte, a descartabilidade da vida, da vida do Outro, o negacionismo que recusa a gravidade da crise vivida no atual momento. ${ }^{47}$

Assim, é urgente o resgate da alteridade, da ética da responsabilidade e do cuidado com o Outro, respeitando sua morada, pois a alteridade do Outro "só é possível se o Outro é realmente o Outro"48. Fundamentado na concepção de ser a partir do

42 Diversos autores abordam a questão da descartabilidade de algumas vidas. Michel Foucault preconizou a passagem do "fazer morrer e deixar viver" para o "deixar morrer e fazer viver"; Giorgio Agambem teorizou sobre o Homo Saccer; também Judith Butler aborda as vidas precárias de grupos vulneráveis; e mais recentemente Achille Mbembe desenvolveu o conceito de necropolítica. Todas essas terminologias versam sobre um olhar utilitarista sobre a vida, no qual uns são mais iguais que outros, nas palavras de George Orwell.

43 LIPOVETSKY, Gilles. Metamorfoses da cultura liberal: ética, mídia e empresa. Trad. Juremir Machado da Silva. Porto Alegre: Sulina, 2004. p. 34.

44 LÉVINAS, 1980, p. 105-106.

45 LIPOVETSKY, 2004, p. 37.

46 ARENDT, 2000, p. 293-295.

47 São fartos os discursos ou postagens de agentes políticos importantes, como Donald Trump, nos Estados Unidos, e Jair Bolsonaro, no Brasil, minimizando os efeitos da pandemia da Covid-19, os quais são exaustivamente repetidos, de modo a ir tomando corpo, negando a gravidade da doença, das descobertas científicas, politizando a economia, a saúde, e a própria vida (SANCHES; MAGENTA, 2020).

${ }^{48}$ LÉVINAS, 1980, p. 24. 
outro $^{49}$, do ser enquanto relação, sujeito não atomizado $0^{50}$, pode-se defender um olhar teórico e prático, científico e dialogal de desconstrução ${ }^{51}$ e reconstrução de um projeto de humanidade baseado na solidariedade, frente à persistente tentação do encastelamento, do egoísmo, do fechamento, nos quais sejamos responsáveis uns pelos outros. O pensamento de Lévinas, como reação à descartabilidade e instrumentalização da vida conduzida pela racionalidade econômica, se mostra cada vez mais necessário como um caminho de redescoberta da necessidade da dependência e responsabilidade que temos uns pelos outros, da necessidade de uma vivência dialógica baseada na alteridade, de uma relação ética que assume o compromisso com a individualidade e, ao mesmo tempo, com a outridade. Essa incumbência é, paradoxalmente, individual e coletiva, científica e das lideranças espirituais, de guiar a um compromisso ético que não se restrinja apenas ao eu.

O pensamento cristão tem a contribuir quando observadas as lições de Cristo, de vida em comunidade, de coletividade. Aderir às recomendações dos profissionais e pesquisadores de saúde, de isolamento social, de uso de máscaras, cuidados com a higiene pessoal e de objetos ${ }^{52}$ é cuidar do Outro, é cuidar da comunidade, do coletivo. Ao mesmo tempo em que as religiões têm o papel de pastoralmente consolar, acalmar, amparar, têm também o dever social e eclesial de estar firme ao lado da defesa da vida. Cuidar da vida, em um momento caótico que uma pandemia gera, é apoiar as medidas sanitárias, é buscar formas de dar lar aos que necessitam fazer isolamento, é propagar uma ética de alteridade, de olhar para o Outro. Ciência e religiões devem estar de mãos dadas para cuidar da vida.

\section{Conclusão}

Viver uma nova pandemia no século XXI nos parece algo estarrecedor, pois, com todo o avanço da ciência, ainda somos dependentes de novas pesquisas e, sobretudo, de novos produtos e tecnologias para promover saúde. A humanidade não imaginava passar por uma experiência tão cruel, ameaçadora e mortal à nossa existência, pois parece que nossa sensibilidade pós-moderna não nos possibilita reviver os medos

49 LÉVINAS, 1980, p. 27-28.

${ }^{50}$ ARENDT, 2000, p. 331.

${ }^{51}$ Na palavra des-construir já há a noção de construção. É uma proposição integrada, conexa, conforme o "brincar" linguístico que Jacques Derrida (2017) propõe.

${ }^{52}$ As intervenções não farmacológicas (INF) são medidas de saúde pública com alcance individual, ambiental e comunitário. As medidas individuais incluem a lavagem das mãos, a etiqueta respiratória e o distanciamento social. O distanciamento social, por sua vez, abrange o isolamento de casos, a quarentena aplicada a contatos, e a prática voluntária de não frequentar locais com aglomerações de pessoas. (GARCIA; DUARTE, 2020). Igualmente, conforme orientação da OMS, o uso de máscaras faz parte de um pacote completo de medidas de prevenção e controle para frear a propagação da Covid-19. O uso de máscaras isoladamente não é suficiente para proporcionar uma adequada proteção ou controle da fonte, e outras medidas nos âmbitos individuais e comunitários também devem ser adotadas para conter a transmissão de vírus respiratórios. Além do uso de máscaras, a adesão a medidas de higienização das mãos, distanciamento físico e outras medidas de prevenção e controle de infecções (PCI) é crucial para prevenir a transmissão inter-humana da Covid-19 (OPAS, 2020b, p. 7). 
do passado, que pareciam ter ficado guardados na memória social. Enquanto humanidade, alimentamos uma esperança de termos construído saberes e espiritualidades capazes de nos proteger das mazelas do passado, como se tivéssemos dado um novo salto na evolução que nos protegesse de ameaças massivas, como as de um passado já distante, mas tão ameaçador em suas permanências. Conhecemos de perto a vivência que líamos nos livros de história, ou que as distopias aspiravam: um vírus letal sofre mutações e passa a contaminar seres humanos de todo o planeta e, cada vez mais, aproxima-se da minha realidade, do meu eu e daquilo que me cerca.

O tempo presente agora nos parece imprevisível, a vulnerabilidade perante à finitude da vida foi escancarada. Uma finitude não natural, mas causada por um vírus de proporções pandêmicas. Já não nos sentimos mais seguros nos lugares onde habitamos. Os lugares são vigiados, segregados, estamos isolados nos nossos próprios espaços de vivência, o lugar nunca esteve tão restrito. Nosso isolamento tornou-se necessário, os espaços de troca tornaram-se virtuais, nos aproximamos por imagens e áudios, o que tornou o espaço cada vez mais relativo. Estamos longe e próximos ao mesmo tempo.

$\mathrm{O}$ isolamento físico trouxe consigo uma série de novas angústias. O contexto da pandemia do novo coronavírus nos causou uma grande quantidade de medos, que talvez suponhamos já superados, mas agora revisitados. Como abordamos na primeira sessão, o medo da morte parece rondar nosso imaginário novamente, não que ele tenha sido eliminado em algum momento da história, mas a ameaça de uma pandemia ressignifica o medo da morte, faz o ser humano temer a antecipação de seu fim, faz com que esse medo emerja de forma angustiante. A história da humanidade nos demonstra que todas as pestes e epidemias causaram medo, mas olhar para a história nos faz, também, compreender as estratégias de resistências.

O medo que nos ronda não é apenas individual, mas sobretudo coletivo, e está fazendo parte do imaginário social do tempo presente. Por isso a importância de pensar na nossa sobrevivência e, principalmente, pensar no Outro, nas nossas relações de alteridade. Relações que, às vezes, nos parecem adormecidas pelo avanço e mesmo defesa do individualismo. Somos individuais e coletivos, vivemos num mundo social, no qual as relações de interação acontecem simultaneamente, por isso essa necessidade do cuidado e proteção do Outro. Gestos muito simples podem ajudar na nossa própria proteção e na do Outro; todas as medidas sanitárias são importantes nesse sentido de preservação da vida humana. Nos casos de pandemias, as medidas de proteção são de extrema importância e responsabilidade de todos. Por isso volta-se a questões muito peculiares de alteridade e respeito à vida humana.

As lições de uma pandemia são muitas, e ainda estamos nos adaptando a elas, pois são formuladas a cada dia que passa. Muitas pessoas perderam suas vidas ao redor do mundo, assim como no nosso país. A imaginação individual e coletiva foi povoada pela representação da doença, pelos seus sintomas, pela sua possível cura, pelas suas sequelas e, principalmente, pelo medo da morte. A representação de uma possível cura é muito forte, as pessoas recorrem a tudo, à ciência, às crenças, às promessas divinas, a todas as forças do universo, tudo em busca de uma segurança para permanecer vivo. 
Neste momento, antes de nos abraçarmos às nossas convicções, às nossas verdades "verdadeiras" 53 , absolutas, cabe respeitar o tempo, o tempo da ciência e o tempo da espiritualidade. Ciência e espiritualidades são históricas, desenvolvem-se dia a dia. A busca pela cura ou pela vacina da Covid-19 demonstra como o conhecimento e o saber precisam ser desenvolvidos e construídos. Da mesma maneira, é preciso traçar caminhos de construção de uma ética da alteridade, de cuidado com o Outro. Esse caminho pode e deve ser construído, também, por meio de uma espiritualidade em que se reconheçam as muitas formas de exercitar e viver a fé, nas mais diversas religiões. Formas essas capazes de despertar e de constituir um verdadeiro olhar filosófico-teológico para a outridade. Assim como em outros momentos históricos as adversidades forjaram novas tecnologias, novos conhecimentos e outros saberes, fazem-se votos para que a pandemia da Covid-19 nos presenteie com esta tecnologia que é de baixa densidade e alta complexidade ${ }^{54}$, a ética da alteridade.

\section{Referências}

ARENDT, Hannah. A Condição Humana. 10. ed. Rio de Janeiro: Forense Universitária, 2000. BAUMAN, Zygmunt. Comunidade. A busca por segurança no mundo atual. Trad. Plínio Dentzien. Rio de Janeiro: Jorge Zahar, 2003.

DELUMEAU, Jean. A história do medo no ocidente 1300-1800: Uma cidade sitiada. Trad. Maria Lucia Machado. São Paulo: Companhia das Letras, 2009.

DERRIDA, Jacques. Gramatologia. 2. ed. São Paulo: Perspectiva, 2017.

FOUCAULT, Michel. Microfísica do poder. 9. ed. Rio de Janeiro; São Paulo: Paz e Terra, 2019. GARCIA, Leila Posenato; DUARTE, Elisete. Intervenções não farmacológicas para o enfrentamento à epidemia da COVID-19 no Brasil. Epidemiologia e Serviços de Saúde, Brasília, v. 29, n. 2, 2020. Disponível em: <https:/www.scielo.br/scielo.php?pid=S223796222020000200100\&script=sci_arttext\#B5>. Acesso em: 22 jul. 2020.

GOES, Emanuelle Freitas; RAMOS, Dandara de oliveira; FERREIRA, Andrea Jaqueline Fortes. Desigualdades raciais em saúde e a pandemia da Covid-19. Trabalho, educação e saúde, Rio de Janeiro, v. 18, n. 3, 2020. Disponível em: < https://preprints.scielo.org/index.php/scielo/preprint/ view/635/816>. Acesso em: 22 set. 2020.

GOMES, Romeu; NASCIMENTO, Elaine Ferreira do; ARAÚJO, Fábio Carvalho de. Por que os homens buscam menos os serviços de saúde do que as mulheres? As explicações de homens com baixa escolaridade e homens com ensino superior. Cadernos de Saúde Pública, v. 23, n. 3, 2007. Disponível em: $<$ https:/www.scielo.br/scielo.php?pid=S0102-311X2007000300015\&script=sci_ abstract\&tlng=pt $>$. Acesso em: 26 jul. 2020.

LEVINAS, Emmanuel. Totalidade e infinito. Trad. José Pinto Ribeiro. Lisboa: Edições 70, 1980.

53 VATTIMO, 2016, p. 14.

54 Terminologia utilizada para descrever o Programa de Atenção Básica, no Sistema Único de Saúde, que se caracteriza por um conjunto de ações de saúde, no âmbito individual e coletivo, que abrange a promoção e a proteção da saúde. O programa utiliza tecnologias de elevada complexidade e baixa densidade, orientadas pelos princípios da universalidade, da acessibilidade e da coordenação do cuidado, do vínculo, da continuidade, da integralidade, da responsabilização, da humanização, da equidade e da participação social. 
LIPOVETSKY, Gilles. Metamorfoses da cultura liberal: ética, mídia e empresa. Trad. Juremir Machado da Silva. Porto Alegre: Sulina, 2004.

OPAS. Organização Pan-americana de Saúde. OMS afirma que COVID-19 é agora caracterizada como pandemia. 11 mar. 2020. Disponível em: <https://www.paho.org/bra/ index.php?option $=$ com_content $\&$ view $=$ article $\&$ id $=6120$ :oms-afirma-que-covid-19-e-agoracaracterizada-como-pandemia\&Itemid=812>. Acesso em: 22 jul. 2020a.

OPAS. Organização Pan-americana de Saúde. Orientação sobre o uso de máscaras no contexto da COVID-19: Orientação provisória 5 de junho de 2020. 05 jun. 2020. Disponível em: $<$ https://iris.paho.org/bitstream/handle/10665.2/52254/OPASWBRACOVID-1920071_por. pdf? sequence $=1 \&$ isAllowed $=\mathrm{y}>$. Acesso em: 22 set. $2020 \mathrm{~b}$.

PAIM, Cynthia Schuck; ALONSO, Wladimir J. Pandemias: saúde global e escolhas pessoais. Alfenas: Cria editora, 2020.

PLATÃO. Leis e Epínomes. Trad. Carlos Alberto Nunes. Pará: Universidade Federal do Pará, 1980. v. 12.

REZENDE, Joffre Marcondes de. Epidemia, Endemia, Pandemia e Epidemiologia. Linguagem Médica, v. 27, p. 153-155, jan./jun. 1998.

SANCHES, Mariana; MAGENTA, Matheus. Bolsonaro e Trump radicalizam: as semelhanças entre os líderes na pandemia de coronavírus. BBC News Brasil. Washington; Londres. 20 abr. 2020. Disponível em: <https://www.bbc.com/portuguese/brasil-52361730>. Acesso em: 20 set. 2020.

SILVA, Carlos Roberto Lyra da; SILVA, Roberto Carlos Lyra da. Dicionário de saúde. 6. ed. São Caetano do Sul: Yendis, 2007.

TASCHNER, Natalia Pasternak. Gripe espanhola: 100 anos da mãe das pandemias. Saúde Abril. São Paulo, 11 mar. 2020. Disponível em: <https://saude.abril.com.br/blog/cientistasexplicam/gripe-espanhola-100-anos-da-mae-das-pandemias/>. Acesso em: 20 set. 2020.

VATTIMO, Gianni. Adeus à verdade. Petrópolis: Vozes, 2016. 